\title{
HIPERHISTÓRIA PARA AUXILIAR A CRIANÇA DO 2 ANO DO ENSINO FUNDAMENTAL EM SEU PROCESSO DE ORTOGRAFIZAÇÃO
}

\author{
Sandra Andrea Assumpção Maria, Centro Universitário La Salle/UNILASALLE \\ Ana Margô Mantovani, Centro Universitário La Salle/UNILASALLE \\ Dirléia Fanfa Sarmento, Centro Universitário La Salle/UNILASALLE \\ \{sandra.andrea, margo, fanfa\}@unilasalle.edu.br
}

\begin{abstract}
Resumo: Neste artigo apresentamos um software educacional, na modalidade de hiperhistória, com atividades lúdicas e didáticas para auxiliar os alunos do $2^{\circ}$ ano do Ensino Fundamental no processo de ortografização. Para a implementação, utilizamos recursos da multimídia e da hipermídia, considerando requisitos técnicos e pedagógicos, tais como interface, interação e feedback. Destacamos também a importância da preservação do meio ambiente trazendo a Floresta Amazônica, cenário da hiperhistória, mais próxima do aluno, através de situações reais que ocorrem na atualidade. Através da avaliação da hiperhistória, em uma escola de ensino privado de Canoas, constatamos que os alunos interagiram de forma ativa na exploração da hiperhistória, demonstrando interesse e entusiasmo na realização das atividades propostas.
\end{abstract}

Palavras-Chave: hiperhistória, ortografização, Floresta Amazônica

\section{HYPERHISTORY TO HELP $2^{\text {nd }}$ YEAR ELEMENTARY SCHOOL STUDENTS IN THEIR SPELLING ACQUISITION PROCESS}

Abstract: In this article we presents an educational software, in hyperhistory mode, with ludic and didactic activities to help $2^{\text {nd }}$ year Elementary School students in their spelling acquisition process. In order to implement the hyperhistory, multimedia and hypermedia devices were used, considering technical and pedagogical requisites such as interface, interaction and feedback. The importance of environmental preservation is highlighted trought the hyperhistory setting, the Amazon Forest. This setting is brought closer to students trought real situations that occur nowadays. By evaluating the hyperhistory, in a private school of Canoas, it was noticed that the students reacted in an active way to the hyperhistory exploration, showing interest and enthusiasm in accomplishing the proposed activities.

Keywords: hyperhistory, spelling, Amazon Forest

\section{Introdução}

As tecnologias digitais virtuais (TDVs) abrem um leque cada vez maior de aplicações educacionais, pois os recursos da multimídia e da hipermídia possibilitam a construção de material educacional com alto grau de interatividade. Neste contexto, podemos pensar no desenvolvimento de software educacional com maior qualidade técnica e pedagógica, que explore estes recursos da melhor forma possível, agregando interação e ludicidade à aprendizagem.

Em um software educacional, as atividades precisam ser variadas e criativas, apresentando, preferencialmente, nível de complexidade, pois quanto maior possibilidades de interação com o software, mais atrativo será para o aluno utilizá-lo, ampliando sua participação e atraindo sua atenção na exploração deste. Estas atividades precisam ser desenvolvidas em um ambiente lúdico, para que os alunos tenham a 
possibilidade de interagir nos diversos cenários apresentados. Estes cenários, além de contribuir no desenvolvimento de competências e habilidades através dos recursos da multimídia e hipermídia, também precisam apresentar situações que favoreçam a tomada de decisões e a capacidade de resolver problemas, a formulação de novas hipóteses, despertem a curiosidade, estimulando a construção do conhecimento.

A hipermídia se caracteriza pela combinação dos recursos da multimídia gerenciados por um sistema de hipertexto. Acredita-se que uma das maiores vantagens da hipermídia é a possibilidade que o usuário tem de interagir com o software. Esta possibilidade de acesso não-linear às informações, permitindo ao usuário uma navegação mais livre, onde ele mesmo decide o que lhe é pertinente num determinado momento, é a principal característica dos sistemas de hipertexto. A aplicação da característica não-linear da hipermídia num ambiente lúdico remete ao conceito de hiperhistórias.

De acordo com Sanchez (1993) hiperhistórias são histórias que ocorrem em um ambiente hipermídia combinando aspectos estáticos e dinâmicos. Apresentam inúmeras vantagens, pois proporcionam que o aluno/usuário seja parte do processo, atuando de forma ativa na construção de sua aprendizagem. Também oferecem ao professor, enquanto usuário, recursos para poder desenvolver aplicações de acordo com suas necessidades e contextualizadas ao seu ambiente.

Desse modo, a utilização dos recursos da hipermídia através de hiperhistórias surge como uma alternativa para tornar um software educacional mais interativo e atraente, principalmente para as crianças. Assim, implementamos uma hiperhistória com atividades lúdicas e didáticas para auxiliar os alunos do $2^{\circ}$ ano do Ensino Fundamental no processo de ortografização. Ainda, neste contexto, trabalhamos com a educação ambiental trazendo a Floresta Amazônica, cenário da hiperhistória, mais próxima do aluno, através de situações reais que ocorrem na atualidade.

\section{Processo de Ortografização}

A alfabetização não pode ser entendida como mera aquisição de uma habilidade mecânica entre a correspondência letra e som, mas sim, como um processo dinâmico e ativo. Alguns métodos utilizados para a alfabetização ensinavam por partes ou elementos das palavras, tais como letras, sons ou famílias silábicas, para depois combiná-los em palavras. A ênfase era a correspondência som-símbolo e o material didático utilizado era basicamente uma cartilha.

No entanto, os estudos sobre a psicogênese da língua escrita, desenvolvidos por Ferreiro e Teberosky (1999), baseados nos pressupostos construtivistas/ interacionistas de Piaget e Vygotsky, comprovam que a criança reconstrói o código lingüístico e reflete sobre a escrita. Estes estudos introduzem uma nova proposta provocando um repensar nos antigos métodos fundamentados em concepções mecanicistas sobre o processo de alfabetização. A preocupação deixa de ser 'como se deve ensinar a escrever', passando para 'como alguém aprende a ler e escrever', independente do ensino. Em outras palavras, o processo desloca-se do ato de ensinar para o ato de aprender, através da construção de um conhecimento que é realizado pela própria criança, que ao invés de ser passiva, recebendo e absorvendo o que lhe é ensinado, participa ativamente desse processo.

Nesta perspectiva, a criança constrói várias hipóteses que caracterizam os níveis de alfabetização, até construir o conhecimento da base alfabética escrita. Então, compete ao professor desenvolver atividades que favoreçam a reflexão da criança sobre a escrita, para que ela possa desestruturar sua concepção atual e avançar nos níveis 
conceituais lingüísticos, porque é pensando que ela aprende. É importante compreender que a aprendizagem da leitura e escrita não acontece da mesma forma para todos os alunos e uma das dificuldades da criança é entender para que serve a língua escrita e o que faremos com ela.

De acordo com os estudos psicogenéticos das autoras referidas, uma vez que a criança alcança a fase alfabética, ela vence a aquisição do código escrito e chega-se à psicogênese da ortografia, ou seja, o aluno chega ao nível de conceitualização. No entanto, conforme Grossi (2001), para construir a convenção social da escrita os alunos encontram algumas dificuldades tais como: o $\mathbf{L}$ e o $\mathbf{R}$ intercalados ou encontros vocálicos, $\mathbf{Z}$ ou $\mathbf{S}, \mathbf{L}$ ou $\mathbf{L H}, \mathbf{G}$ ou $\mathbf{J}$, como chegar ao $\mathbf{N H}, \mathbf{l}$, $\mathbf{U}$ e $\mathbf{O}$ no final das palavras, sinal da nasalização, o emprego do $\mathbf{H}, \mathbf{C}, \mathbf{S}, \mathbf{S S}$, os sons do $\mathbf{X}$, entre outras. Ainda para a autora, a leitura é um dos melhores caminhos para se chegar a uma escrita ortográfica, mas é necessário que o aluno seja o primeiro leitor de tudo o que escreve, passando a ser o seu próprio revisor.

Neste sentido, Zorzi (2003) destaca que a apropriação do sistema ortográfico de escrita se dá em uma progressão evolutiva, tendo em vista que aprender a escrever implica compreender uma série de propriedades ou aspectos da língua escrita que fazem parte do sistema ortográfico. Segundo o autor, a apropriação progressiva do sistema ortográfico passa pelos seguintes conceitos: diferenciação do traçado das letras, consciência fonológica, identificação da posição das letras dentro da palavra, diferenciação da linguagem oral da linguagem escrita, compreensão das múltiplas representações escritas de um mesmo som. Dentre esses aspectos, descreve também algumas das principais dificuldades que podem ser encontradas por crianças do $2^{\circ}$ Ano do Ensino Fundamental, tais como: Representações Múltiplas; Oralidade; Omissão de letras; União ou Separação de Sílabas; Terminações em AM e AO; Generalizar regras; Grafia de fonemas surdos e sonoros; Acréscimo de letras; Confusão entre letras parecidas; Inversões de letras.

Para auxiliar as crianças nesta trajetória rumo à escrita ortográfica, torna-se necessário apresentar atividades lúdicas que as motivem a ler e escrever. Para tal, o professor precisa se sentir desafiado e responsável por esse processo, assumindo esse importante papel de proporcionar situações de aprendizagem diversificadas que levem à criança a compreender as diferenças entre a língua falada e a língua escrita.

Assim, na tentativa de superar ou minimizar as dificuldades encontradas pela criança em seu processo de ortografização, desenvolvemos uma hiperhistória com atividades lúdicas e didáticas que correspondem às características desse processo.

\section{Hiperhistórias: Conceituação e metodologia de desenvolvimento}

Segundo Sánchez (1993), as hiperhistórias são, de certo modo, a versão eletrônica das histórias convencionais, do mesmo modo que os hipertextos são a versão eletrônica dos textos. Para o autor, as hiperhistórias são histórias que ocorrem dentro de um ambiente virtual hipermidial, que combinam aspectos estáticos e dinâmicos, permitindo a interação por todo o ambiente. Através do uso de tecnologias baseadas em multimídia interativa, é possível integrar o uso de imagens, cores, som, vídeo, texto e animação que possibilite ao aluno o controle e a manipulação desses objetos. Ainda para o autor, possuem uma história principal com sub-histórias que são acessadas conforme a ação do usuário levando-o de leitor, a explorador e construtor, através da interação propiciada pelas estruturas dos sistemas hipermídia. Esta possibilidade de interação com os diversos cenários apresentados aguça a curiosidade da criança, instigando-a a explorar a hiperhistória. 
Procuramos levantar no estado da arte, metodologias para o desenvolvimento de uma hiperhistória, porém encontramos apenas a metodologia desenvolvida por Sanchez et al. $(1993 ; 1995 ; 1996)$, sendo esta metodologia adotada para a implementação dessa hiperhistória. Em relação à implementação da interface, além desses autores, também consideramos os estudos de Winckler (1999).

Segundo Sanchez e Lumbreras (1996), uma hiperhistória possui três elementos fundamentais: contextos, ligações e entidades. Os contextos representam os ambientes (telas), ou seja, os espaços pelos quais a criança irá navegar, podendo ainda, dependendo da história, possuir outros sub-contextos que são definidos como subespaços desse mesmo ambiente. As ligações contemplam o relacionamento de um ambiente a outro, através da utilização de objetos específicos. Também são responsáveis por indicar ao explorador quando não há possibilidades de ligação. E por sua vez, as entidades são os objetos (estáticos ou dinâmicos) e personagens que se incluem na história. A utilização de objetos e personagens devem ser adequados à história, pois possuem a finalidade de interligar sub-histórias, manipular atividades e o ambiente como um todo e, ainda, mediar e auxiliar o aluno em sua exploração no ambiente. Diversas metáforas podem ser implementadas a partir do modelo especificado, tais como: uma cidade, uma casa, uma floresta, etc.

O desenvolvimento de uma hiperhistória deve atender aos requisitos técnicos e pedagógicos de qualidade de software educacional tais como, interface, interação/mediação e feedback.

A interface é um elemento imprescindível para a aceitação da aplicação interativa por parte do usuário, independente do tipo de aplicação. Devemos considerar alguns fatores determinantes para fins educacionais, tais como: telas bem coloridas e nítidas para que se tornem agradáveis ao público infantil; botões grandes e de fácil execução, que possibilite uma fácil navegabilidade no programa; atividades variadas e criativas. A interface demanda diversos cuidados, principalmente porque se trata da ligação direta com o aluno, ou seja, será ela que vai ser o canal principal de comunicação e interação.

Destacamos também a importância do feedback tanto para os acertos, quanto para erros, pois será através de um feedback construtivo que o aluno poderá refletir sobre o erro e construir hipóteses para uma nova tentativa na realização de suas atividades.

Como ferramenta de desenvolvimento optamos pela utilização do software de autoria Adobe Flash CS3 Professional, por apresentar estruturas e apresentações adequadas e da ferramenta Adobe Photoshop CS3 Extended para desenvolver e criar os contextos, ligações e entidades da hiperhistória.

\section{Descrição da hiperhistória: Floresta Amazônica - Uma aventura Ecológica}

A história principal é baseada na preservação da natureza. Ações concretas e exemplos de ações conscientes em relação aos cuidados com o meio ambiente foram representados através de atividades lúdicas e didáticas, com o objetivo de auxiliar os alunos do $2^{\circ}$ ano do Ensino Fundamental no processo de ortografização. Este tema foi escolhido pensando nos eixos temáticos mais importantes e emergentes do mundo.

No início da hiperhistória o aluno pode escolher entre um menino ou uma menina, ambos são protagonistas, conforme a Figura 1. Após, a arara azul convida o aluno a digitar o seu nome. Escolhemos a arara azul para ser o personagem mediador da história por ser um animal em extinção. É este personagem que realizará a interação com o aluno, pois vai acompanhá-lo em todas as atividades e contextos, indicando orientação e feedback de acerto e erro. 


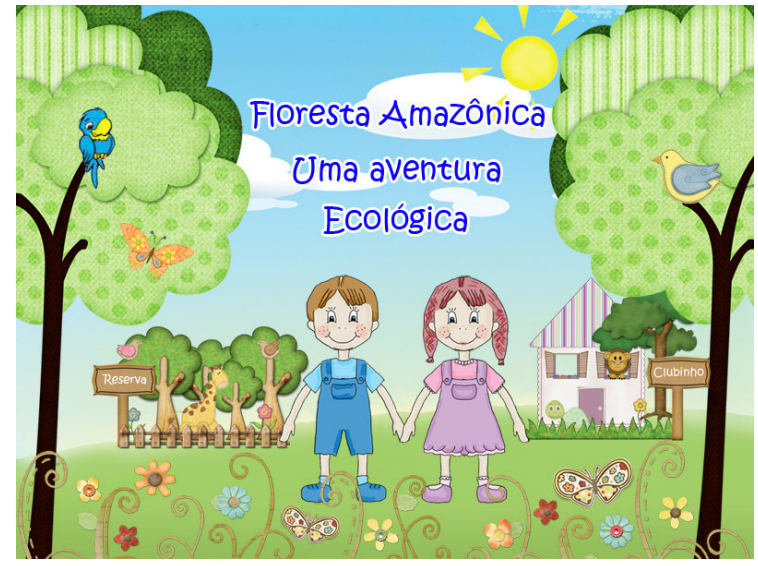

Figura 1 - Tela inicial da hiperhistória

A história inicia no contexto principal: Floresta Amazônica. Neste contexto o aluno pode escolher entre conhecer e visitar o Clubinho Ecovida ou a Reserva Ecológica. Independente da opção escolhida e em qualquer um dos contextos, o aluno pode a qualquer momento alternar entre os caminhos e tem a liberdade de voltar e escolher outra atividade em outro contexto. Da mesma forma, em todas as atividades o aluno tem a opção de sair da aplicação. Ao escolher esta opção, o aluno será levado para outro contexto que realizará uma animação final com uma mensagem e o fará sair da hiperhistória.

Para navegar entre os contextos, o aluno precisa apenas dar um clique sobre o local que quer conhecer. Além disso, o aluno também conta com outras opções de interação na hiperhistória, tais como: botões que constam em todas as atividades (botão atividade, botão exemplo, botão vídeo, botão curiosidades, botão atividade extra e botão sair), o botão voltar (permite retornar ao contexto anterior), botão guia do professor, botões de áudio e botões de acesso às atividades.

Ao optar entrar no Clubinho Ecovida (Figura 2) o aluno poderá escolher entre as três atividades abaixo, bem como voltar ao contexto anterior ou sair da hiperhistória:

- Aprendendo a separar o lixo - Atividade: Recolha o lixo;

- Água - fonte de vida - Atividade: Papa-letras;

- Aquecimento global - Atividade: Decifre a palavra.

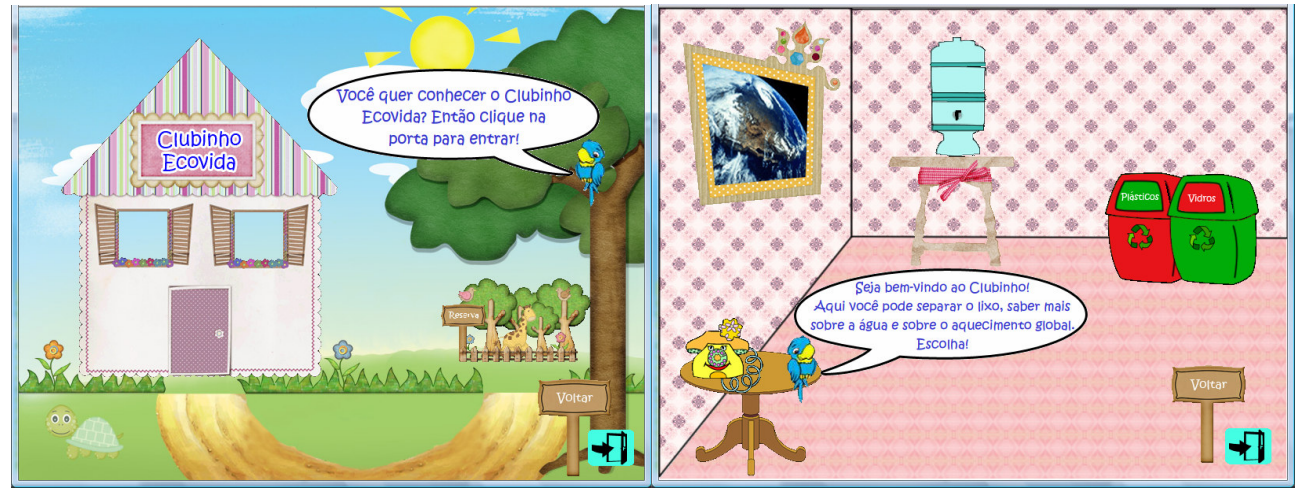

Figura 2 - Contexto Clubinho Ecovida 
Ao entrar na Reserva Ecológica (Figura 3) o aluno poderá escolher entre as três atividades mostradas a seguir, bem como voltar ao contexto anterior ou sair da hiperhistória:

- A cultura indígena - Atividade: Mensagem Secreta;

- Animais em extinção - Atividade: De quem é o som?

- Habitat natural - Atividade: Onde você mora?

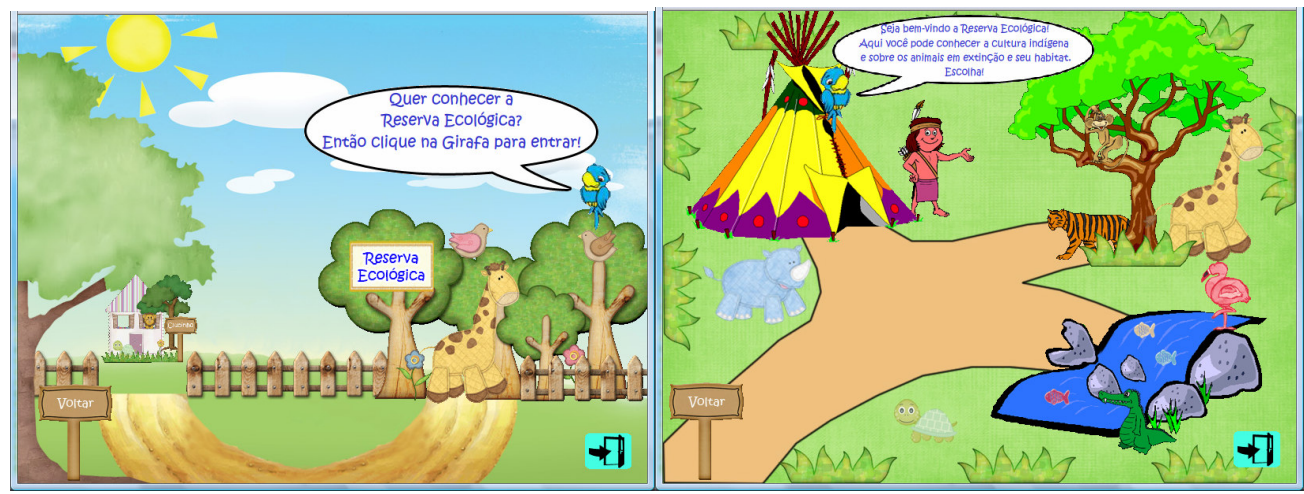

Figura 3 - Contexto Reserva Ecológica

\subsection{Descrição das atividades e feedback}

Para a elaboração das atividades, levamos em consideração alguns aspectos, tais como: as dificuldades ortográficas descritas por Grossi (2001) e Zorzi (2003), a relação com o contexto da história e com as atividades realizadas em sala de aula bem como o feedback adequado à situação e construtivo. Desenvolvemos seis atividades, conforme apresentamos na Tabela 1 - Atividades da hiperhistória.

Tabela 1- Atividades da hiperhistória

\begin{tabular}{|c|c|}
\hline $\begin{array}{l}\text { 1) Contexto: Clubinho Ecovida } \\
\text { Atividade: Recolha o lixo }\end{array}$ & 2) Contexto: Clubinho Ecovida \\
\hline Recolna o lixo! & 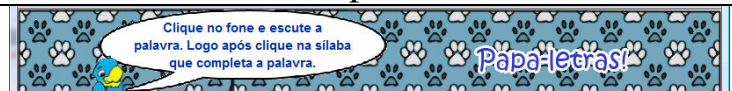 \\
\hline & PRA \\
\hline Figura 4 - Atividade "Recolha o lixo!" & Figura 5 - Atividade "Papa-letras!" \\
\hline $\begin{array}{l}\text { Descrição da atividade: Observe as latas de } \\
\text { lixo. Uma é para os vidros, outra é para os } \\
\text { papéis e a última é para os plásticos. Arraste } \\
\text { os objetos para a lata de lixo correta } \\
\text { conforme a sua escrita correta. } \\
\text { Dificuldade ortográfica trabalhada: }\end{array}$ & $\begin{array}{l}\text { Descrição da atividade: quando a palavra } \\
\text { for pronunciada o aluno deve clicar na sílaba } \\
\text { que faz parte da palavra. } \\
\text { Dificuldade ortográfica trabalhada: } \\
\text { confusão entre letras parecidas. } \\
\text { Exemplo: planeta - praneta - graneta. }\end{array}$ \\
\hline
\end{tabular}




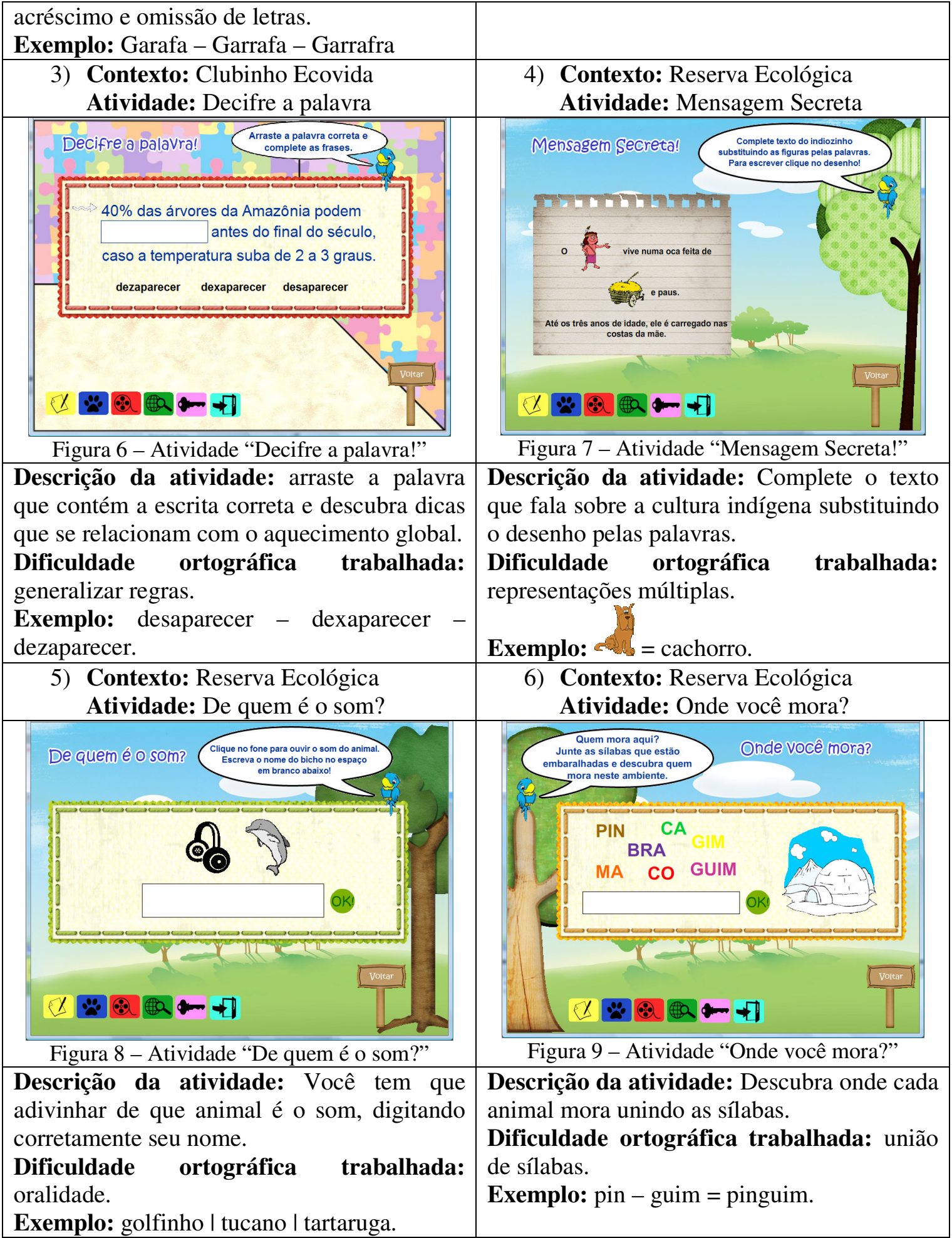

Tivemos grande preocupação na construção do feedback, pois entendemos que é importante o aluno ter um retorno que mostre ou diferencie o certo do errado, principalmente com relação ao erro, para não ser tratado como uma reprovação, mas, sim, que proporcione reflexões através da mediação realizada. Um feedback que possa auxiliar a criança a compreender a possível causa de uma determinada situação de erro 
e, a partir dessa reflexão, levá-la a uma correta tomada de decisão. Para atender estes requisitos e considerando o ciclo "descrição-execução-reflexão-depuração" proposto por Valente (1999), implementamos em todas as atividades três tipos de feedback para o erro e um feedback para o acerto:

- $1^{\circ}$ Erro: o personagem mediador fornece uma mensagem possibilitando ao aluno refletir sobre o erro e solicita para realizar a atividade novamente. Dependendo da atividade, o aluno ainda pode recorrer a um recurso diferente, como, por exemplo, clicar no fone e ouvir a pronúncia correta da palavra;

- $2^{\circ}$ Erro: padronizamos em todas as atividades um auxílio através dos botões de navegação, ou seja, se o aluno erra pela segunda vez, o personagem mediador orienta o aluno a clicar nos botões "Atividade" e "Exemplo". Apresenta-se uma explicação de como a atividade deve ser realizada e um exemplo para o aluno ter como apoio, respectivamente (Figura 10);

- $3^{\circ}$ Erro: a aplicação mostra a palavra correta e o personagem mediador indica, através de uma mensagem, que o aluno pode realizar novamente a atividade quando desejar (Figura 11). Logo após, a aplicação o direciona para o contexto anterior;

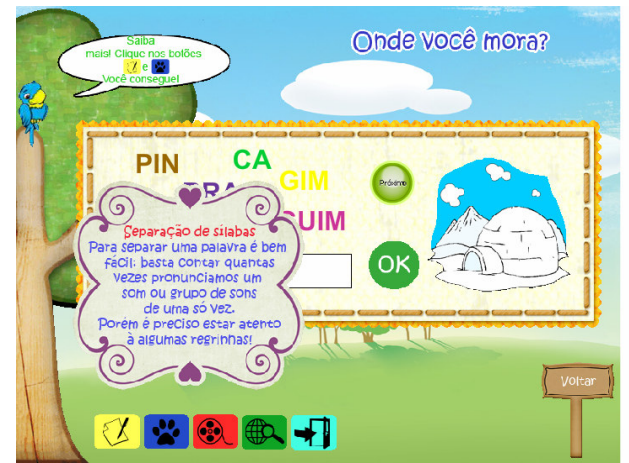

Figura 10 - Feedback do $2^{\circ}$ erro

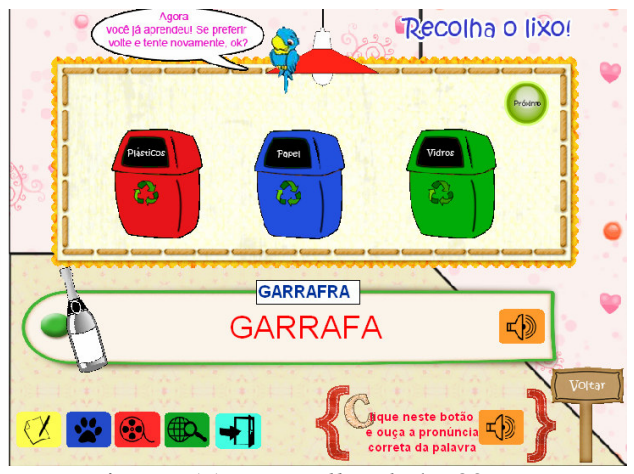

Figura 11 - Feedback do $3^{\circ}$ erro

- Feedback de acerto: para motivar o aluno a continuar a realização das atividades, apresenta-se uma mensagem do personagem mediador e uma animação.

\section{4. Avaliação da hiperhistória}

A hiperhistória foi avaliada com uma turma do $2^{\circ}$ ano de Ensino Fundamental de uma escola de ensino privado de Canoas, sendo utilizados como instrumentos: um questionário aplicado com a professora para avaliar a hiperhistória nos principais aspectos técnicos e pedagógicos e os possíveis avanços na construção do conhecimento do nível ortográfico; a observação do interesse das crianças na interação com o software e as dificuldades encontradas em relação à interface e atividades propostas. A partir desses dados podemos constatar que:

- em relação à interação e interface: houve interação tanto com a hiperhistória, quanto como os colegas, principalmente diante da descoberta de um novo recurso ou caminho ainda não explorado; tiveram um grande interesse na utilização da hiperhistória, pois percebemos que buscavam explorar os diversos recursos e mídias disponíveis; de modo geral, não houve dificuldades de navegação, os alunos conseguiram explorar a hiperhistória e realizar as atividades sem necessitar de ajuda; somente após navegar por todos os caminhos e conhecer todos os contextos é que os 
alunos realizaram as atividades e acessaram os demais botões de navegação; através desses botões, descobriram outros recursos multimídia;

- em relação à realização das atividades alguns alunos comentaram que já conheciam determinadas palavras, pois tinham aprendido em sala de aula, àqueles que obtinham resultados satisfatórios davam seguimento às demais atividades, por outro lado, àqueles que tinham mais dificuldade, mesmo passando pelos três tipos de feedback, retornavam à atividade e a realizavam novamente;

- o personagem mediador teve um papel importante neste processo, pois através deste o aluno foi motivado a dar continuidade na realização das atividades e orientado em relação aos procedimentos diante de algum erro; - Sinalizamos que, mesmo com a facilidade na utilização da hiperhistória, o professor é sempre fundamental neste processo, pois é na busca de seu auxílio que o aluno irá se reportar quando da impossibilidade de navegar ou realizar uma atividade.

\section{Considerações Finais}

Percebemos que os alunos sentiram-se motivados ao interagir com a hiperhistória, e que as atividades propostas podem ajudá-los em um futuro próximo, no processo de ortografização, através de um planejamento de sua utilização, onde se possa acompanhar o avanço e os processos de aprendizagem dentro de um determinado período, tanto no laboratório de informática quanto em sala de aula. Alertamos aqui para a importância do professor, enquanto um mediador dessas interações e do processo de (re) construção do conhecimento dos alunos.

O feedback foi pensado de acordo com as diversas atividades e contextos, bem como buscamos propor um momento de reflexão para o aluno, de modo que fosse possível repensar o erro e que o motivasse a realizar a atividade novamente, ou então verificar que acertou e, a partir do feedback construtivo dar continuidade às demais atividades. De modo geral, os feedback construídos foram considerados adequados, pois tivemos o cuidado de elaborá-los em vários níveis para garantir que o ciclo proposto por Valente (1999) se fizesse presente.

Neste sentido, constatamos ainda que, o personagem mediador teve um papel muito importante, pois ele foi o responsável por reportar ao aluno o feedback das atividades e orientá-lo na realização das atividades. Seu papel teve um destaque importante, pois a partir dos feedback construtivos, em níveis diferenciados e personalizados, ou seja, de acordo com o contexto que se encontrava o aluno, permitiu a sua reflexão, o que de fato é essencial para sua vivência em seu contexto escolar.

$\mathrm{Na}$ etapa que se refere ao desenvolvimento das atividades, buscamos oferecer atividades conhecidas e semelhantes das realizadas em sala de aula, de forma que o aluno conseguisse compreender o que precisava ser feito, mas que permitisse que o mesmo tivesse a experiência de conhecer outros desafios. Consideramos importante apontar que, para perceber os possíveis avanços em relação à ortografia, seriam necessárias mais interações com o software, pois somente através do seu uso constante, bem como com o acompanhamento da professora titular em sala de aula, é que poderíamos de fato, ter resultados mais significativos.

\section{Referências Biliográficas}

CAMPOS, M. de B.; LIMA, J. V. de; SANCHEZ, J. Hiperhistórias na educação: um meio de educação/reeducação psicomotora. In: SIMPÓSIO BRASILEIRO DE 
INFORMÁTICA NA EDUCAÇÃO, 6., 1995, Florianópolis. Anais... Santa Catarina: SBC, 1995.

FERREIRO, E.; TEBEROSKY, A. Psicogênese da língua escrita. Porto Alegre: Artmed, 1999.

GROSSI, E. P. Série Didática Pós-Piagetiana: jogos para alfabetização. Erechim: Ed. Edelbra. 2001.

MARCONI, M. A. de.;LAKATOS, E. M. Técnicas de Pesquisa. $6^{\text {a }}$ ed. São Paulo: Atlas, 2006.

SÁNCHEZ, J. L. Informática Educativa. Editorial Universitária. Santiago. Chile. 1993.

SÁNCHEZ, J. L. LUMBRERAS, M. Analisis de una metodologia para construir Hiperhistórias. Congresso Iberamericano de Informática Educativa. Barranquilla, 1996.

THIOLLENT, M.. Metodologia da pesquisa-ação. 11. ed. São Paulo, SP: Cortez, 2002.

TRIVIÑOS, A. N. S. Introdução à pesquisa em ciências sociais: a pesquisa qualitativa em educação. São Paulo: Atlas, 2001.

VALENTE, J. A. O Computador na Sociedade do Conhecimento: Informática na Educação no Brasil. Análise e Contextualização Histórica. Coleção Informática para a mudança na Educação. Ministério da Educação (MEC), 1999.

ZORZI, J. L Aprendizagem e Distúrbios da Linguagem Escrita: questões clínicas e educacionais. Porto Alegre: Artmed, 2003.Winckler (1999). 